\title{
Perspectives on Networking with Other Dentists
}

Disclaimer: The use, mention or depiction of any product, device, service or appliance shall not be interpreted as an endorsement, recommendation or preference by the AADSM. Any opinion expressed is solely the opinion of the individual, and not that of the AADSM.

The practice of dental sleep medicine requires dentists to manage a multitude of moving parts. Beyond caring for patients themselves, clear channels of communication with other providers are essential for helping a patient meet their treatment goals. Additionally, fostering solid relationships with other nearby treating practitioners can also help a dentist build their referral network.

While many may focus their network-building and communication strategies on physicians, it is also very important to include other dentists into this mix. We reached out to several of our members to hear their thoughts on how they build quality relationships with other dentists in their area and build strong communication channels with patients' general dentists.

\section{WHAT ARE SOME STRATEGIES THAT YOU HAVE USED TO BUILD YOUR REFERRAL NETWORK WITH OTHER DENTISTS IN YOUR AREA?}

"One strategy is to make personal connections with dentists in your area and offer educational opportunities for their practices. This is something you can do whether you work for a dental sleep organization (DSO) or in private practice. When I worked for a DSO, I got a list of all the affiliated dentists in my area. I created my own lunch \& learn presentation and set up sessions with the various offices within my DSO network to bring awareness of and educate about dental sleep medicine. I use this same strategy now that I am in private practice, but now focus my outreach on local study clubs and/or dentists I have met through dental society events."

\section{- Eric Runyon, DDS, D.ABDSM}

"[Some of the strategies I use are:] attending local dental society meetings and building rapport with dental specialists who do sedation through letters of introduction and requests for direct meet and greets."

\section{- Jennifer Le, DMD, D.ABDSM}

"I have done informational sessions and provided literature on OSA to dentists in my area. I have also reached out to my network of specialists, to whom I have been referring cases to over the years (endodontists, orthodontists, pedodontists, periodontists and oral surgeons). I have given them information about the OSA treatment services that I provide. Working with specialists has been especially beneficial as they can also reinforce my recommendations to a patient who may be reluctant to proceed with treatment. Lastly, I've made complimentary appliances for some general dentists and dental specialists so that they can see the benefits of oral appliance therapy first hand (as long as they meet treatment guidelines)."

\section{- Rubina Nguyen, DDS, D.ABDSM}

\section{WHAT ARE SOME TIPS FOR NAVIGATING RELATIONSHIPS WITH A PATIENT'S GENERAL DENTIST?}

"When interacting with a patient's general dentist, I always keep in mind the golden rule of treating others how you would like to be treated. For example, when I refer a patient to a specialist, I prefer specialists who make the process easy for the patient and my office team, do great work they stand behind, and keep me in the loop with communication. When I treat patients for sleep apnea, we communicate at each step of the process from initial consult to delivery of the device and subsequent follow-up. However, we also engage with the office staff of the general dentist to ask about their preferences on frequency, mode of communication, etc., so we can best keep the general dentist team happy. Getting feedback can be key in solidifying a relationship and creating the best experience for the patient, dental team, and general dentist."

\section{- Eric Runyon, DDS, D.ABDSM}

"[I recommend] communicating directly with your patients both your role and their dentists' roles in successful management of OSA. Make sure that you are able to be reachable directly by patients' dentists ,so that they feel confidence in your partnership."

- Jennifer Le, DMD, D.ABDSM 
"It's important that your services are limited to treating OSA. Patients should be sent back to their general dentist upon completion of treatment. If dental work is needed, the general dentist should be consulted and be the one providing the treatment. There are also many dentists who provide some oral appliance therapy, but their practices are not limited to sleep dentistry. For those offices, you can offer to take on their difficult cases. If there are procedures that you don't do, refer them to your local dental office. Being a source of referrals goes a long way to creating goodwill and strengthening relationships with general dentists."

\section{CITATION}

Perspectives on Networking with Other Dentists. J Dent Sleep Med. 2022;9(1).
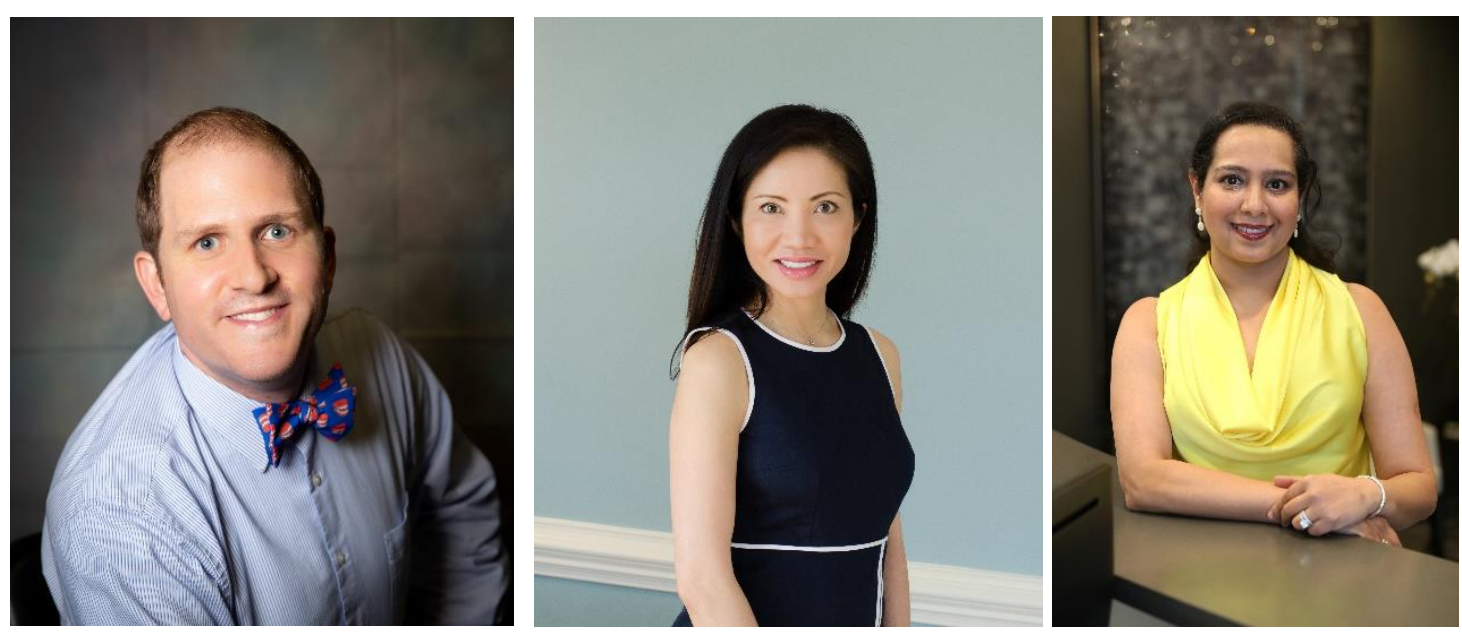

Left to Right: Dr. Eric Runyon, Dr. Jennifer Le, Dr. Rubina Nguyen 